\title{
ADESÃO ÀS PRECAUÇÕES PADRÃO ENTRE OS PROFISSIONAIS DA EQUIPE DE RESGATE PRÉ- HOSPITALAR DO CORPO DE BOMBEIROS DE GOIÁS
}

\author{
ADHESION ACE PRECAUTIONS STANDARD BETWEEN THE PROFESSIONALS OF THE TEAM OF DAILY \\ PAY-HOSPITAL RESCUE OF THE BODY OF GOIÁS FIREMEN \\ ADHERENCIA A LAS MEDIDAS DE PRECAUCIONES ESTÁNDARES ENTRE LOS PROFESIONALES DEL \\ EQUIPO DEL RESCATE DE PRÉ-HOSPITALAR DEL CUERPO DE BOMBEROS DE GOIÁS
}

\section{Valéria Borba FLORÊNCIO ${ }^{1}$ Carolina de Araujo RODRIGUES ${ }^{2}$ Milca Severino PEREIRA ${ }^{3}$ Adenícia Custódia Silva e SOUZA ${ }^{3}$}

RESUMO : Este estudo teve como objetivo identificar a compreensão dos profissionais da equipe de Resgate PréHospitalar do Corpo de Bombeiros de Goiás acerca dos riscos de exposição a material biológico e a adesão às medidas de precauções padrão. Os dados foram coletados através de questionário e observação sistematizada. A única medida de segurança adotada se restringe ao uso de luvas de procedimentos, foi demonstrado pouco conhecimento acerca das medidas de proteção e dos riscos a que estão expostos. A equipe apresenta competência técnica para os atendimentos de socorro a vítimas, mas necessita de preparo para sua autoproteção.

PALAVRAS-CHAVES: Precauções padrão; Atendimento pré-hospitalar; Biossegurança.

ABSTRACT: This study it had as objective to identify to the understanding of the professionals of the team of PayHospital Rescue of the Body of Firemen of Goiás concerning the exposition risks the biological material and the adhesion to the measures of precautions standard. The data had been collected through questionnaire and systemize comment. The only measure of adopted security if restricts to the use of gloves of procedures, had demonstrated to little knowledge concerning the measures of protection and the risks the one that is displayed. The team presents ability technique for the attendance for the victims and needs preparation for its self-protection.

KEY-WORDS: Standard precautions; Emergency attendance; Bio - security.

RESUMEN: Este estudio teve como objetivo identificar la comprensión de los profesionales del equipo del rescate de Pré-Hospitalar del Cuerpo de Bomberos de Goiás referente a los riesgos de la exposición el material y la adherencia a las medidas de precauciones estándares. Los datos habían sido recogidos a través de cuestionario y sistematizan el comentario. La única medida de seguridad adoptada de sí restringe al uso de guantes de procedimientos, fue demostrada a poco conocimiento referente a las medidas la protección y los riesgos el se exhibe que. El equipo presenta a técnica de la capacidad para la atención e ayuda a las víctimas, pero necesita la preparación para su uno mismo-protección.

TERMINOS CLAVES: Precauciones estándares; atención diarios del pagar-hospital; biossegurança.

\section{INTRODUÇÃO}

O conceito de sistema de emergência préhospitalar no Brasil surgiu a partir de 1986, com a criação do Grupo de Socorros de Emergência (GSE) do Corpo de Bombeiros do Rio de Janeiro, com a incorporação de médicos socorristas e unidades de suporte avançado de vida (HARGREAVES, 2000).

Em 1999, com a portaria no 824 GM de 24 de junho, o Ministério da Saúde considerou como atendimento pré-hospitalar aquele procedimento prestado à vítima nos primeiros minutos após ter ocorrido o agravo à sua saúde (BRASIL,1999).

ocupacionais, principalmente, por manusear de forma direta ou indireta materiais orgânicos excretados e secretados por clientes portadores de patologias desconhecidas, podendo, por sua vez, ser fonte de

${ }^{1}$ Enfermeira do Programa Saúde da Família - borba@betanet.com.br
${ }^{2}$ Enfermeira

${ }^{3}$ Enfermeiras. Doutoras em Enfermagem - Docentes da Faculdade de Enfermagem da Universidade Federal de Goiás. Rua 227, Qd 68 s/n (FEN/UFG); Setor Leste Universitário. CEP 74605-080, Goiânia (GO).
No Estado de Goiás, o Grupamento de Resgate Pré-hospitalar (GRPH) do Corpo de Bombeiros Militar foi estruturado no ano de 1997 e desde então, tem desempenhado importante papel no atendimento a vítimas. Só em 2001, o grupo prestou atendimentos a 13624 vítimas. Diante deste dado ressaltamos a importância social e humanitária das ações desenvolvidas pelo grupo de resgate. $O$ alto grau de profissionalismo e a precisão técnica conquistaram a confiança do cidadão, que se sente seguro ao ser atendido por este serviço.

Ao realizar atendimento pré-hospitalar, os profissionais estão constantemente expostos a vários riscos durante a execução de suas atividades transmissão de microrganismos para os profissionais e outras vítimas.

Para reduzir o risco de transmissão, principalmente, de hepatite B e HIV são necessárias medidas preventivas para proteger tanto o 
profissional quanto o cliente do contato com sangue, particularmente através de ferimentos percutâneos. Estas medidas incluem a utilização de instrumentos, técnicas e práticas de trabalho mais seguras e, ainda, uso consistente de barreiras de proteção apropriadas (HOEFEL \& SCHNEIDER, 1997).

Em 1996, os Centers for Diseases Control and Prevention (CDC) editaram as precauções padrão as quais devem ser adotadas para o atendimento a todos os clientes independente do conhecimento do seu estado infeccioso. Tal norma inclui apropriada lavagem das mãos e o uso de luvas para o manuseio de todos os fluidos orgânicos, dentre outros (GARNER, 1996).

No atendimento de emergência pré-hospitalar, observamos que os riscos de contaminação dos profissionais aumentam na proporção direta em que há contatos mais intensos e diretos com as vítimas.

De acordo com a estatística de ocorrência do GRPH, os atendimentos a vítima estão distribuídos nas categorias de acidentes de trânsito, emergências clínicas, intoxicação, lesão térmica, suicídio, entre outros.

Todos os atendimentos oferecidos pelo GRPH proporcionam condições de risco de contaminação com fluídos corpóreos. Este fato requer a adesão as medidas de precauções padrão para proteção do profissional.

Entretanto, ressaltamos que em nossa experiência, os profissionais da equipe de resgate pré-hospitalar, diante de algumas situações, muitas vezes, utilizavam os Equipamentos de Proteção Individual (EPI) de forma inadequada, ficando expostos a riscos de contaminação. Questionamos se estes profissionais não fazem uso das medidas de precauções padrão, por não estarem conscientes do risco à que estão expostos ou por não terem incorporado ao hábito o uso destas medidas.

Considerando que a equipe de resgate préhospitalar trabalha em condições de alto risco ocupacional, há necessidade de verificar o conhecimento e adoção, dos profissionais, as medidas protetoras relacionadas à prevenção das doenças.

\section{OBJETIVOS}

Verificar a compreensão dos profissionais do GRPH do Corpo de Bombeiros de Goiás, acerca dos riscos de exposição a material biológico

Identificar a adesão às medidas de precauções padrão pelos profissionais do GRPH do Corpo de Bombeiros de Goiás

Levantar fatores intervenientes na adesão às precauções padrão pelos profissionais do GRPH do Corpo de Bombeiros de Goiás.

\section{DELINEAMENTO DA PESQUISA}

\footnotetext{
${ }^{1}$ Enfermeira do Programa Saúde da Família - borba@betanet.com.br

${ }^{2}$ Enfermeira

${ }^{3}$ Enfermeiras. Doutoras em Enfermagem - Docentes da Faculdade de Enfermagem da Universidade Federal de Goiás. Rua 227, Qd $68 \mathrm{~s} / \mathrm{n}$ (FEN/UFG); Setor Leste Universitário. CEP 74605-080, Goiânia (GO).
}

Estudo realizado junto às equipes de resgate do GRPH do Corpo de Bombeiros Militar do Estado de Goiás, localizado no município de Goiânia-GO.

Fizeram parte da pesquisa todos os ligados diretamente ao atendimento a vítimas, que estavam trabalhando no período da coleta de dados, e concordaram em participar da pesquisa através da assinatura do termo de livre consentimento.

Foram incluídos todos os socorristas atuantes no atendimento pré-hospitalar, e excluídos os que se encontravam em férias, licença médica, operações externas ao município, que não estavam ligados ao resgate da vítima ou que recusaram em participar.

Os dados foram coletados, após a observação dos aspectos ético-legais referentes á pesquisa em seres humanos, através de um questionário que foi respondido pelos participantes do estudo, logo após receberem o plantão e antes de saírem para os atendimentos.

O questionário abordava os seguintes temas: compreensão dos profissionais a respeito de precauções padrão e risco biológico; imunização dos profissionais; utilização de medidas de segurança em procedimentos que oferece riscos de respingo, formação de aerossóis, secreção e fluídos corpóreos; facilidades e dificuldades na utilização dos EPI; lavagem das mãos; descarte de materiais perfurocortantes; acidentes com materiais perfurocortantes e condutas tomadas e treinamentos específicos sobre precauções padrão.

Além dos dados do questionário, que evidenciaram a compreensão dos profissionais acerca dos riscos ocupacionais, procedeu-se a observação direta, dos riscos biológicos a que estão expostos e da adoção das medidas de precauções padrão durante as atividades no atendimento e resgate.

A observação foi realizada em cada uma das equipes de resgate, no mínimo em 4 situações de atendimento. Foi utilizado um roteiro para observação sistematizada com as seguintes categorias préestabelecidas: utilização dos EPI - indicação para o uso, uso adequado e forma de descarte; artigos utilizados nos atendimentos: forma de descarte de artigos contaminados e forma de reprocessamento dos artigos reutilizados e condutas adotadas em situações de risco com material biológico.

Os instrumentos usados para a obtenção dos dados foram validados quanto ao seu conteúdo, mediante avaliação feita por quatro enfermeiros, os quais foram selecionados por atuarem na área de controle de infecção hospitalar ou segurança do trabalho.

Os resultados foram interpretados e analisados à luz dos princípios norteadores da prática de assistência de qualidade com redução dos riscos ocupacionais, utilizando-se, ainda, referências acerca de segurança do trabalho e de medidas de precauções padrão preconizadas pelos CDC. profissionais da equipe de resgate pré-hospitalar 


\section{RESULTADOS E DISCUSSÃO}

A instituição pesquisada possui um total de 78 profissionais, destes 34 foram excluídos por não atenderem aos critérios de inclusão. Participaram do estudo, 44 profissionais sendo 34 socorristas, 5 enfermeiros, 3 médicos e 2 motoristas.

O GRPH possui dois tipos de atendimento: uma Unidade de Resgate Básico (UR) composta por socorristas, os quais não tem formação na área da saúde, realizando somente atendimentos primários como função de imobilização, contenção de hemorragias e transporte de vítimas; e uma Unidade de Suporte Avançado (EUA) composta por socorristas, enfermeiro e médico, na qual se realiza atendimentos mais complexos tipo reanimação cardíaca, procedimentos invasivos, contenção de hemorragias, entre outros.

$A$ equipe de resgate manifestou seu entendimento acerca de precauções padrão conceituando-as como a utilização de EPI ou medidas de proteção à saúde ou cuidados de proteção na realização do trabalho.

As medidas de segurança mencionadas pela equipe de resgate, para realizar procedimentos que oferecem risco de contato com sangue e outros fluídos corpóreos compõem a Tabela 1.

TABELA 1 - Medidas de seguranças ocupacionais adotadas para a realização de procedimentos considerando o tipo de contato. GRPH - Corpo de Bombeiros, Goiânia, 2001.

\begin{tabular}{|l|c|c|c|c|}
\hline \multirow{2}{*}{ Medidas de segurança adotadas } & \multicolumn{2}{|c|}{$\begin{array}{c}\text { Contato direto com } \\
\text { secreções }\end{array}$} & \multicolumn{2}{c|}{$\begin{array}{l}\text { Contato através de } \\
\text { respingo }\end{array}$} \\
\cline { 2 - 5 } & $\mathrm{N}^{0}$ & $\%$ & $\mathrm{~N}^{\circ}$ & $\%$ \\
\hline Luvas de procedimentos & 42 & 95,45 & 38 & 86,36 \\
\hline Luvas estéreis & 07 & 15,90 & 05 & 11.36 \\
\hline Máscara & 42 & 95,45 & 43 & 97,72 \\
\hline Óculos protetores & 39 & 88,63 & 38 & 86,36 \\
\hline Gorro & 20 & 45,60 & 22 & 50,00 \\
\hline Outros & 06 & 13,48 & 03 & 6,81 \\
\hline & & & & \\
\hline
\end{tabular}

Ao serem questionados acerca do uso de medidas de segurança houve o predomínio da utilização de luvas de procedimentos, máscaras e óculos protetores durante situações de risco. No entanto, através da observação realizada durante o atendimento a vítima, constatamos que a única medida utilizada, em tais situações, foi o uso de luvas de procedimento. Verificamos que em algumas vezes, durante $o$ atendimento, a equipe se expôs ao material biológico através de respingo de sangue em mucosas de olho, boca e nariz.

Durante a observação detectamos que apesar dos profissionais usarem luvas de procedimento, estes não têm o devido cuidado em evitar a contaminação da superfície, pois manuseiam pranchetas, macas, maçanetas e outros objetos sem retirar as luvas. Desta forma, as luvas utilizadas como equipamento de proteção individual tem se transformado em equipamento de disseminação de contaminantes. Este comportamento tem sido igualmente constatado em outras situações de atendimento pela equipe de saúde, inclusive em hospitais.

A adesão ao uso do EPI está intimamente relacionada á percepção que os profissionais têm acerca dos riscos a que estão expostos e da susceptibilidade a estes riscos. Neste estudo, evidenciamos que os profissionais banalizam os riscos ocupacionais com material biológico, não sabendo, na sua maioria, identificar as conseqüências decorrentes da inobservância do uso de medidas de prevenção.

Observamos, também, que a maioria dos profissionais, principalmente socorristas, não faz uso adequado de equipamentos de segurança no momento da lavagem dos equipamentos contaminados e do veículo da unidade de resgate. Esta é realizada em um pátio, sem um sistema de escoamento adequado, ficando a água da lavagem dos materiais represada em uma quadra de esporte.

É importante considerar que a água retida na quadra de esporte contamina o ambiente de trabalho da corporação. Todo o ambiente no qual se acondiciona ou reprocessa material contaminado, deve possuir superfícies laváveis e ser provido de torneiras e ralos com escoamento direto para rede de esgoto.

Durante a execução da limpeza manual é necessário o uso de EPI, ou seja, luvas grossas de borracha antiderrapantes, aventais impermeáveis, botas, gorro, óculos protetores (SOBECC, 2001).

Detectamos que luvas contaminadas com sangue e outras secreções corpóreas são desprezadas em lixo comum, em recipientes abertos expostos a insetos, estas condutas somadas ao manuseio de pranchetas, caneta, maçaneta, maca com luvas contaminadas estendem o risco de contaminação ambiental e coletiva. Além disso, existe a possibilidade dos próprios profissionais se contaminarem ao manusear superfícies por eles mesmos contaminadas.

\footnotetext{
${ }^{1}$ Enfermeira do Programa Saúde da Família - borba@betanet.com.br

${ }^{2}$ Enfermeira

${ }^{3}$ Enfermeiras. Doutoras em Enfermagem - Docentes da Faculdade de Enfermagem da Universidade Federal de Goiás. Rua 227, Qd $68 \mathrm{~s} / \mathrm{n}$ (FEN/UFG); Setor Leste Universitário. CEP 74605-080, Goiânia (GO).
} 
O lixo deve ser selecionado como resíduos infectantes quando proporciona risco potencial a saúde pública e ao meio ambiente devido à presença de agentes biológicos, ou lixo comum quando não oferece risco adicional a saúde pública. O lixo infectante deve ser acondicionado em saco plástico branco, identificado com o símbolo de substância infectante, disposto em lixeira com tampas que as fechem hermeticamente, e o seu volume não pode ultrapassar $2 / 3$ da capacidade da lixeira (RIBEIRO FILHO, 2000).

Outra importante medida de proteção refere-se à imunização. Os profissionais que assistem a pacientes devem estar imunizados com o objetivo de proteção individual, interrupção da disseminação de doenças infecciosas e proteção indireta de pessoas não vacinadas ${ }^{8}$. Verificamos a situação vacinal dos profissionais pesquisados, sendo que 17 deles afirmaram estar com o esquema completo da vacina contra hepatite B e 23 estavam com o esquema incompleto tendo recebido apenas a primeira dose; 24 foram imunizados contra tuberculose; 32 iniciaram o esquema de tétano e difteria, destes 26 fizeram a segunda dose e apenas 21 completaram o esquema; 18 receberam a tríplice viral; 7 vacinaram contra febre amarela.
A adesão ao esquema vacinal pela equipe de resgate é baixa, considerando que as vacinas estão disponíveis na rede básica para os profissionais de saúde e que algumas delas fazem parte de campanhas, portanto, de fácil aceso.

Foi nos relatado que apesar do risco com material biológico, que os profissionais da equipe de resgate estão expostos, não há exigência quanto à comprovação do esquema vacinal no momento da admissão ao serviço e nem orientação quanto à importância da imunização. Além do quem, alguns socorristas referiram não ter conhecimento da necessidade de se fazer o reforço de algumas vacinas. Estes dados denotam a baixa percepção do risco, o desconhecimento de medidas protetoras e a pouca preocupação em adotar medidas sabidamente eficazes e seguras.

Apesar da eficácia das precauções padrão, estas têm sido pouco observadas, principalmente, quanto ao uso dos EPI, que até se tornarem integrantes da rotina dos profissionais, mostram-se como incômodos e difícies de serem aceitos ${ }^{7}$. Diante disso verificamos quais as dificuldades encontradas pelos profissionais, quanto à utilização de EPI durante a realização de procedimentos (Tabela 2 ).

TABELA 2 - Dificuldades indicadas pelos profissionais do grupo de resgate para a adoção de medidas de segurança. GRPH - Corpo de Bombeiros, Goiânia, 2001.

\begin{tabular}{|l|c|c|}
\hline Dificuldades & $\mathbf{N}^{\mathbf{0}}$ & $\mathbf{\%}$ \\
\hline Sobrecarga de trabalho & 32 & 72,7 \\
\hline Falta de cursos específicos & 21 & 47,7 \\
\hline Falta de material (EPI) & 16 & 36,3 \\
\hline Falta de incentivo & 13 & 29,5 \\
\hline Situações de emergência & 13 & 29,5 \\
\hline Falta de água, sabão e papel toalha & 14 & 31,8 \\
\hline Falta de tempo & 09 & 20,4 \\
\hline Dificuldade de adaptação ao EPI & 06 & 13,6 \\
\hline Falta de hábito & 04 & 9,0 \\
\hline
\end{tabular}

A maioria relatou que a principal dificuldade é a sobrecarga de trabalho. A sobrecarga de trabalho além de deixar o profissional mais estressado exige maior rapidez na execução das tarefas e muitas vezes induz a um fazer repetitivo sem adequado planejamento.

Destacamos que 16 profissionais $(36,3 \%)$ relataram falta de material para própria proteção, o que não foi confirmado pelas observações. $\mathrm{Na}$ verdade, não há um planejamento da distribuição destes materiais, pois o profissional responsável em repor os mesmos é membro da equipe e nem sempre verifica o estoque na unidade de resgate.

$\mathrm{O}$ atendimento em situações de emergências é relatado pela equipe como um fator que favorece a exposição aos riscos biológicos, devido ao caráter emergencial não permitir que o profissional se paramente e, também, pela rapidez com que os procedimentos muitas vezes são realizados. No entanto, ressaltamos que todos os atendimentos prestados pelo GRPH são considerados de emergência, sendo por isso necessário que o profissional se paramente adequadamente antes de chegar ao local da ocorrência, pois desconhece a situação em que se encontra a vítima.

Mesmo diante de situações de emergência é necessário que os profissionais adotem as medidas de precauções padrão, inclusive a lavagem das mãos. Assim, indagamos se havia local adequado para a lavagem das mãos, $37(84,1 \%)$ responderam de forma negativa e $5(11,4 \%)$ responderam de forma afirmativa. Os locais referidos como adequados foram: pias e torneiras no hospital e central de operações. E os dois restantes $(4,5 \%)$ não responderam.

Apesar de cinco $(11,4 \%)$ relatarem um local apropriado para lavagem das mãos, os locais citados são inviáveis já que o profissional não tem condições

${ }^{1}$ Enfermeira do Programa Saúde da Família - borba@betanet.com.br

${ }^{2}$ Enfermeira

${ }^{3}$ Enfermeiras. Doutoras em Enfermagem - Docentes da Faculdade de Enfermagem da Universidade Federal de Goiás. Rua 227, Qd 68 s/n (FEN/UFG); Setor Leste Universitário. CEP 74605-080, Goiânia (GO). 
de lavar as mãos antes e após o atendimento à vítima, uma vez que as UR e USA não possuem pias.

A despeito disso, ressaltamos que soluções alternativas podem ser implementadas, como o uso de álcool gel a 70\% para a lavagem das mãos em situações nas quais, por qualquer motivo, não tenha acesso fácil e imediato a pia com água e sabão ${ }^{9}$. Salientamos, no entanto, que os profissionais devem realizar a lavagem simples das mãos com água e sabão ao chegarem nos hospitais ou na central de operações, pois apesar da eficácia do álcool gel, ele não substitui a lavagem das mãos.

Questionamos os profissionais a respeito das facilidades encontradas para a adoção de medidas de segurança, as respostas obtidas estão apresentadas na Tabela 3.

TABELA 3 - Facilidades encontradas pelos profissionais da equipe de resgate para a adoção de medidas de segurança. GRPH - Corpo de Bombeiros, Goiânia, 2001.

\begin{tabular}{|c|c|c|}
\hline Facilidades & $\mathbf{N}^{\mathbf{0}}$ & $\%$ \\
\hline Segurança na realização das tarefas & 39 & 88,6 \\
\hline Disponibilidade de EPI & 27 & 61,3 \\
\hline Conhecimento acerca dos riscos de contaminação/acidente de trabalho & 25 & 56,8 \\
\hline Incentivo e orientação sobre a necessidade de utilização dos EPI & 21 & 47,7 \\
\hline Incentivo dos colegas & 08 & 18,1 \\
\hline Disponibilidade de um recipiente adequado para o descarte de perfurocortantes & 02 & 4,5 \\
\hline
\end{tabular}

Alguns profissionais assinalaram como facilidades a segurança na realização das tarefas, porém este é um fato traiçoeiro, pois o excesso de confiança na rotina de trabalho leva à banalização dos riscos podendo contribuir para aumentar a exposição dos profissionais aos riscos biológicos, uma vez que os acidentes são imprevisíveis e que na rotina de trabalho, nem sempre tudo acontece da mesma forma.

Observamos uma contradição entre as respostas dadas por dois pesquisados sobre 0 descarte de perfurocortantes. As UR e USA não possuem recipientes de paredes rígidas, adequados para o descarte. Os perfurocortantes são depositados em cubas rim sem reencape para, posteriormente, serem desprezados no lixo hospitalar, onde nem sempre são acondicionados em recipiente de paredes rígidas.

Os artigos perfurocortantes devem ser descartados em caixas coletoras imediatamente após o uso (GARNER,1996). O manuseio de perfurocortantes após o uso tem sido responsável pela maioria dos acidentes percutâneos (SOUZA,2001),

As injúrias percutâneas ocorrem, principalmente, durante o descarte, desencaixe ou reencapamento de agulhas, ou ainda, quando o paciente se move abruptamente (HAIDUVEN,1995).

Mesmo tendo possibilidade de prevenir acidentes através da utilização de medidas de seguridade ocupacional, as exposições ao material biológico ainda podem ocorrer. Nestes casos, é indicado imediatamente lavar a área exposta com água e sabão e procurar o médico do trabalho, que fará o registro de Comunicação de Acidente de Trabalho (CAT). O profissional que atende 0 acidentado deve avaliar a gravidade da exposição e tomar as condutas necessárias de acordo com o caso (CALVACANTE \& PEREIRA, 2000).
Dentre os profissionais da equipe de resgate, 12 já tiveram algum acidente de trabalho com material biológico, e 28 nunca se acidentaram. Dos que se acidentaram, cinco referiram exposição a sangue ou outro fluido corpóreo em pele não íntegra e 4 referiram esta exposição em mucosa. Ressaltamos que acidentes com perfurocortantes tiveram um relato baixo, de apenas um caso, porque somente a USA realiza procedimentos com estes materiais.

Imediatamente após o acidente com exposição ao material biológico as condutas tomadas, na maioria, foram à lavagem com água e sabão ou utilização de produtos como solução anti-séptica e a não notificação do acidente. Estes dados evidenciam desconhecimento em relação a estas medidas.

Quando questionados a respeito de treinamento específico sobre precauções padrão após a admissão no serviço de resgate, obtivemos 22 respostas negativas e 21 respostas positivas referindo melhorias das suas atividades após 0 treinamento.

Os temas abordados estavam relacionados a cuidados com a vítima e sua segurança sem enfoque às precauções padrão. Provavelmente, devido ao fato de que estes treinamentos, normalmente, eram ministrados por profissionais que não pertencem à área de saúde.

O treinamento em serviço, apesar de por si não ser suficiente para a adesão às precauções padrão, quando associadas a outros fatores tem contribuído para aumentar a adesão a estas medidas.

Considerando o que foi exposto, temos que os principais fatores intervenientes na adesão às medidas de precaução padrão entre a equipe de resgate pré-hospitalar do Corpo de Bombeiros são: o desconhecimento dos riscos e das medidas protetoras; o fato de não realizarem procedimentos invasivos nas unidades de resgate, que os levam a descartarem a possibilidade de contaminação e não perceberem o risco a que estão expostos; apesar de

\footnotetext{
${ }^{1}$ Enfermeira do Programa Saúde da Família - borba@betanet.com.br

${ }^{2}$ Enfermeira

${ }^{3}$ Enfermeiras. Doutoras em Enfermagem - Docentes da Faculdade de Enfermagem da Universidade Federal de Goiás. Rua 227, Qd 68 s/n (FEN/UFG); Setor Leste Universitário. CEP 74605-080, Goiânia (GO).
} 
se ter treinamento sobre precauções padrão, os responsáveis pela sua execução são profissionais que não estão tecnicamente habilitados acerca desta temática. De acordo com a portaria $n^{0}$ 2616, preferencialmente, o profissional indicado para realizar ações de prevenção a acidentes com material biológico é o enfermeiro (BRASIL, 1998).

\section{CONCLUSÃO}

A partir da análise dos dados coletados acerca da adesão às medidas de precauções padrão, pela equipe de resgate do GRPH do Corpo de Bombeiros de Goiás, constatamos:

- A maioria dos profissionais demonstrou pouco conhecimento sobre precauções padrão;

A adesão ao esquema vacinal dos profissionais é baixa;

- A medida de segurança adotada pela maioria dos profissionais se restringe ao uso de luvas de procedimentos;

- Os acidentes com secreções orgânicas em pele não íntegra foram as formas mais freqüentes de exposição a material biológico;

- A maioria dos profissionais não sabe como proceder após exposição a material biológico;

- Grande parte dos profissionais não tem percebido os riscos a que estão expostos e o risco de contaminação cruzada;

- A maioria dos treinamentos foi realizada por profissionais que não são da área de saúde o que muito prejudicou na elucidação do tema;

- O lixo infectante não é acondicionado e transportado de maneira adequada, proporcionando risco de contaminação aos profissionais e ao ambiente;

- Os perfurocortantes não são descartados em recipientes adequados, favorecendo possíveis acidentes com os mesmos;

- A lavagem manual dos artigos contaminados é realizada em local inapropriado e sem a utilização correta dos EPI.

- Aos profissionais do GRPH do Corpo de Bombeiros do Estado de Goiás desempenham um trabalho fundamental para a comunidade. Entretanto, expõe-se a riscos biológicos pela não adoção de medidas preventivas. A não adoção dessas medidas está relacionada ao pouco conhecimento.

- Acreditamos que a implementação de um treinamento que aproveite as experiências prévias destes profissionais direcionados para as necessidades de seguridade ocupacional garantiria maior segurança para aqueles que oferecem segurança nas situações emergenciais.

\section{REFERÊNCIAS BIBLIOGRÁFICAS}

BRASIL. Ministério da Saúde. Portaria n² 2616, 12 de maio de 1998. Regulamenta o programa de Controle de Infecção Hospitalar no País. Diário Oficial da União, Brasília, p. 133, 13 de maio de 1998. Seção 1. BRASIL. Mistério da Saúde. Portaria nº 824 GM de 24 de junho de 1999. Estabelece normas relativas ao atendimento pré-hospitalar. Disponível em www.uvp5.univ-paris5.fr/SAMU/documPO/doc2.asp [ capturado em 07 de março de 2001].

CALVACANTE, NJF, PEREIRA, NA. Saúde Ocupacional. In: FERNANDES, AT, FERNANDES, MOV, RIBEIRO FILHO, N. Infecção Hospitalar e suas Interfaces na Área de Saúde. São Paulo (SP): Atheneu, 2000, p. 1287-1300.

GARNER, JS. Guideline for isolation precautions in hospitals. Infect. Control Hosp. Epidemiol. 1996; 17 (1): 54-80.

HAIDUVEN, DJ et al. Percutaneous injury analysis: consistent categorization, efective reduction methods, and fure strategies. Infect. Control Hospital. Epidemio..16, (10): 15, 82-589, 1995.

HARGREAVES, LHH. Sistema de Emergência PréHospitalar. In: TIMERMAN, S, RAMIRES, JAF, BARBOSA, JLV, HARGREAVES, LHH. Suporte Básico e Avançado de Vida em Emergências. Brasília (DF): Câmara dos Deputados. Coordenação de Publicações, 2000, p.437-457.

HOEFEL, HHK, SCHNEIDER, LOO. Profissional de Saúde na Cadeia Epidemiológica. In: RODRIGUES, EAC, MENDONÇA, JS, AMARANTE, JMB, ALVES FILHO, MB, GRINBAUM, RS, RICHTMANN, R. Infecções Hospitalares - prevenção e controle. São Paulo (SP): Sarvier, 1997, p.352-366.

RIBEIRO FILHO, N. Gerenciamento de Resíduos de serviços de Saúde. In: FERNANDES, AT, FERNANDES, MOV, RIBEIRO FILHO, N. Infecção Hospitalar e suas Interfaces na Área de Saúde. São Paulo (SP): Atheneu, 2000, p.1156-1200.

SOBECC - Sociedade Brasileira de Enfermeiros de Centro Cirúrgico, Recuperação Anestésica e Central de Material e Esterilização. Centro de Material e Esterilização. Práticas recomendadas da SOBECC. 2001. Cap.1, p.12-30.

SOUZA, ACS, Risco Biológico e Biossegurança no Cotidiano de Enfermeiros e Auxiliares de Enfermagem. [Tese]. Ribeirão Preto (SP): Escola de Enfermagem de Ribeirão Preto/USP; 2001.

Texto original recebido em 24/03/2003

Publicação aprovada em 27/06/2003

\footnotetext{
${ }^{1}$ Enfermeira do Programa Saúde da Família - borba@betanet.com.br

${ }^{2}$ Enfermeira

${ }^{3}$ Enfermeiras. Doutoras em Enfermagem - Docentes da Faculdade de Enfermagem da Universidade Federal de Goiás. Rua 227, Qd $68 \mathrm{~s} / \mathrm{n}$ (FEN/UFG); Setor Leste Universitário. CEP 74605-080, Goiânia (GO).
} 